\title{
Integrative Medicine in New Mexico
}

\author{
Guzman CEV1 and Dinallo AM²* \\ ${ }^{1}$ Morehouse School of Medicine, Georgia, USA \\ 20regon College of Oriental Medicine, USA
}

${ }^{*}$ Corresponding author: Anna M Dinallo, Oregon College of Oriental Medicine, 75 NW

Policy Article

Volume 2 Issue 3

Received Date: April 06, 2018

Published Date: May 15, 2018 Couch Street, Portland OR, 97209, USA, Tel: 505-280-4670; Email: ana.dinallo@ocom.edu

\begin{abstract}
It Is Time for Integrative Medicine: This policy brief provides a current state of affairs with regards to complementary and alternative medicine in Mexico. In collaboration with the Department of Integrative Health and Medical Message located at Taos, Mexico and with the University of New Mexico Center for Life, we conducted a qualitative study that assessed the barriers and success. Key themes that emerged centered on finances, power, and stigma. We recommend crafting policies and devoting resources to emphasize the creation of inter-professional educational and increasing awareness of consumer rights. These are critical given our current fragmented and expensive health care system.
\end{abstract}

Keywords: Complementary and Alternative Medicine; Healing; Herbalist; Acupuncturist; Yoga Therapist.

Abbreviations: CAM: Complementary and Alternative Medicine.

\section{Policy Article}

\section{Complementary and Alternative Medicine (CAM) in New Mexico}

Complementary and Alternative medicine (CAM) [1] refers to a range of health systems, modalities, and practices that are not part of conventional and politically dominant health systems. According to the National Institute of Health, when non-mainstream practices are used together with conventional medicine, it's considered "complementary" When non-mainstream practices are used in place of conventional medicine, it's considered 'alternative".
Integrated medicine brings conventional and complementary approaches together in a coordinated way. This integration provides the provider and patients the option to use non-mainstream approaches alongside with conventional treatment.

There are challenges. For example, the insurance billing and short treatment windows do not align well for (mind, body, and sprit).

Few studies have explored the New Mexico context. Conduced over 100 interviews at eight clinic sites. They found judgment, lack of initiative, and concerns about safety as key barriers that limited complementary medicine. In 2017, a New Mexico survey found 35\% utilizes some kind of traditional treatments. There is a growing recognition that Western medicine has focused too heavily on reductionist frameworks and approaches. 


\section{Journal of Natural \& Ayurvedic Medicine}

Clients' narratives and stories are essential to healing and health. Western medicine is slowly waking up to the power of illness narrative and other modalities of healing [2]. We contribute to this body of literature given New Mexico's rich diversity.

\section{Integrated Medicine Study: Methods and Results}

Researchers organized a regional conference, Building Bridges, targeting practicing providers in the state of New Mexico. This conference took place over the course of two days in April, 2017. Herbalist, acupuncturist, yoga therapist, and other traditional medicine providers were invited to speak. Afterwards, we held two focus groups that discussed barrier and solutions with bridging Western and traditional medicine [3-6].

A total of 32 attended Building Bridges. Eight participated in one focus group and six in the second. Participants' background included medial doctors, pharmacist, and physical therapist, to complementary providers such as traditional health educators, yoga therapist, herbalist and a doctor of Chinese medicine [7$10]$.

\section{Theme One: Finances}

Participants discussed the economic incentives that exist for health care systems. A yoga therapist said, "So much of the physicians' salaries are tied to performance: how much patients you see a day and how much you bill." Discussions highlighted the financial elements of the medical system that ultimately maximized profit over patient care.

\section{Theme Two: Power}

Traditional providers reported a dislike towards being referred to as alternative or complementary. A traditional healer said, "It is funny how Chinese medicine and Ayurvedic medicine have been around for thousands of years and yet they are the alternative" The language utilize conveys power dynamics that must be addressed in order to be equal.

\section{Theme Three: Stigma}

A medial provider shared, "I have a patient who had a tremendous amount of emotional distress from having a miscarriage. I was trying to refer her to acupuncture but she wasn't allowed time off from work...it had that stigma." Participants discussed even more mainstream treatment still struggle with the issue of stigma.
As a follow-up to the focus group findings, we distributed a brief survey for medical doctors at the Integrative Conference, Simply Spicy. The survey inquired about referral practices, training, and barriers. $60 \%$ of providers always refer CAM therapies to their patients and $90 \%$ felt medical doctors would benefit from additional training in CAM therapies.

\section{Protect Equal and Full Access to Integrated Care}

\section{There remain structural and cultural barriers to integrating Western medicine and Complementary medicine. The following are two policy considerations for New Mexico.}

- Inter-professional Training: In New Mexico there are modalities of CAM that do not require a license or formal training program under the New Mexico "Unlicensed Health care Practice Act" HB 664. This protects traditional complementary healers but their training remains in silos. To address financial, power, and stigma barriers more inter-professional training early on must be a priority to build bridges [11-16].

- Consumer Rights: Increasing patients' awareness to integrate both modalities for maximum gain remains absent. New Mexico has a number of Senate Memorial to increase people's access to traditional, cultural, complementary and alternative health care therapies. Senate Memorial 20, 21, and 48 were introduced in 2006 and 2007 but has yet to be adopted. It is necessary to ensure the protection of patient's rights to improve market choice outcomes in a capital driven health care system.

\section{References}

1. Astin JA, Pelletier KR, Marie A, Haskell WL (2000) Complementary and alternative medicine use among elderly persons: One-year analysis of a Blue Shield Medicare supplement. J Gerontol A Biol Sci Med Sci 55(1): M4-M9.

2. Jobst KA, Shostak D, Whitehouse PJ (1999) Diseases of meaning: Manifestations of health, and metaphor. J Altern Complement Med 5(6): 495-502.

3. Astin JA (1998) Why patients use alternative medicine: Results of a national study. JAMA 279(19): 1548-1553. 


\section{Journal of Natural \& Ayurvedic Medicine}

4. Committee on the use of complementary and alternative medicine (2005) Complementary and alternative medicine (CAM) in the United States, National Academies Press. Washington, DC.

5. Eisenberg DM, Kessler RC, Foster C, Norlock FE, Calkins DR, et al. (1993) Unconventional medicine in the United States: prevalence, costs and patterns of use. New England Journal of Medicine 328 (4): 246252.

6. Eisenberg DM, Davis RB, Ettner SL, Appel S, Wilkey S, et al. (1998) Trends in alternative medicine use in the United States 1990-1997: results of a follow up national study. JAMA 280(18): 1569-1575.

7. De Bruyn T (2000) Taking stock: Policy issues associated with complementary and alternative health care. Health Systems.

8. Division, Health Promotion and Programs Branch, Health Canada, Ottawa, ON.

9. Humpel N, Jones SC (2006) Gaining insight into the what, why, and where of complementary and alternative medicine use by cancer patients and survivors. Eur J Cancer Care (Engl) 15(4): 362-368.

10. Kelner M, Wellman B (1997) Health care and consumer choice: medical and alternative therapies. Soc Sci Med 45 (2): 203-212.
11. Kesler DO, Hopkins LO, Torres E, Prasad A (2015) Assimilating traditional healing into preventive medicine residency curriculum. American journal of preventive medicine 49(5): S263-S269.

12. Nelder KH (2000) Complementary and Alternative Medicine. Dermatological Clinics. 18(1): 189-193.

13. Ramsay C, Walker M, Alexander J (1999) Alternative medicine in Canada: use and public attitudes. Public Policy Sources 21, Fraser Institute.

14. Shen J, Andersen R, Albert PS, Wenger N, Glaspy J, et al. (2002) Use of complementary/ alternative therapies by women with advanced stage breast cancer. BMC Complement Altern Med 2: 8.

15. National Center for Complementary and Alternative Medicine (NCCAM) The Use of Complementary and Alternative Medicine in the United States Bethesda, MD: National Institutes of Health; December 2008.

16. Wolsko PM, Eisenberg DM, Davis RB, Ettner SL, Phillips RS (2002) Insurance coverage, medical conditions, and visits to alternative medicine providers: Results of a national survey. Arch Intern Med 162(3): 281-287. 